\title{
Effect of Aspect Ratio, Channel Orientation, Rib Pitch-to-Height Ratio, and Number of Ribbed Walls on Pressure Drop Characteristics in a Rotating Channel with Detached Ribs
}

\author{
K. Arun and S. V. Prabhu \\ Department of Mechanical Engineering, Indian Institute of Technology, Mumbai 400 076, Bombay Powai, India
}

Received 6 May 2006; Revised 20 September 2006; Accepted 30 October 2006

Recommended by Sadanari Mochizuki

\begin{abstract}
The present work involves experimental investigation of the effects of aspect ratio, channel orientation angle, rib pitch-to-height ratio $(P / e)$, and number of ribbed walls on friction factor in orthogonally rotating channel with detached ribs. The ribs are separated from the base wall to provide a small region of flow between the base wall and the ribs. Experiments have been conducted at Reynolds number ranging from 10000-17000 with rotation numbers varying from $0-0.38$. Pitch-to-rib height ratios (P/e) of 5 and 10 at constant rib height-to-hydraulic diameter ratio $(e / D)$ of 0.1 and a clearance ratio $(C / e)$ of 0.38 are considered. The rib angle of attack with respect to mainstream flow is $90^{\circ}$. The channel orientation at which the ribbed wall becomes trailing surface (pressure side on which the Coriolis force acts) is considered as the $0^{\circ}$ orientation angle. For one-wall ribbed case, channel is oriented from $0^{\circ}$ to $180^{\circ}$ about its axis in steps of $30^{\circ}$ to change the orientation angle. For two-wall ribbed case, the orientation angle is changed from $0^{\circ}$ to $90^{\circ}$ in steps of $30^{\circ}$. Friction factors for the detached ribbed channels are compared with the corresponding attached ribbed channel. It is found that in one-wall detached ribbed channel, increase in the friction factor ratio with the orientation angle is lower for rectangular channel compared to that of square channel for both the pitch-to-rib height ratios of 5 and 10 at a given Reynolds number and rotation number. Friction factor ratios of two-wall detached ribbed rectangular channel are comparable with corresponding two-wall detached ribbed square channel both under stationary and rotating conditions.
\end{abstract}

Copyright ( $) 2007$ K. Arun and S. V. Prabhu. This is an open access article distributed under the Creative Commons Attribution License, which permits unrestricted use, distribution, and reproduction in any medium, provided the original work is properly cited.

\section{INTRODUCTION}

In heat exchanger applications, ducts with rib turbulators are used to augment the convective heat transfer. In case of ribs attached to the wall, due to the presence of recirculation zones at the back and in front of the ribs, the local heat transfer rate drops significantly in this region. To avoid formation of such recirculation zones, ribs are detached (positioned at a small distance) from the wall. Fujita et al. [1] investigated forced convection heat transfer on a flat plate with zero pressure gradient in which a single circular cylinder was inserted normal to the free stream direction and positioned at a clearance from the plate. They found that heat transfer enhancement could be achieved with a suitable selection of the clearance. Kawaguchi et al. [2] investigated the heat transfer augmentation with a number of circular cylinders positioned in a line and attached to or near one wall at various streamwise pitches by measuring the heat transfer coefficient. They found that among the pitch to cylinder diameter ratios $(6.25,12.5,25,50, \infty)$ tested, the values 12.5 and 25 were appropriate as far as overall heat transfer augmentation is concerned.

Oyakawa et al. [3] studied the effect of geometric shape (a straight band plate, an angled band plate, and a $\mathrm{T}$ band plate) and clearance of the turbulence promoters, which were set in staggered arrangement on the heat transfer augmentation in the fully developed region of a rectangular duct. Some shapes of turbulence promoters were found to provide a marked improvement in thermal performance as compared with the previously reported cylinder case. For duct flows with a staggered array of circular cylinders near two opposite walls, Yao et al. [4] found that, after the first three cylinders, an almost fully developed state was attained thermally and hydrodynamically and that a more than three times larger 
averaged Nusselt number, relative to that in the smooth duct flow, can be achieved. Moreover, the measured distribution of the local Nusselt number was found to be similar in shape regardless of the Reynolds number $\left(8 \times 10^{3}<R e<6 \times 10^{4}\right)$.

Liou et al. [5] studied the effect of clearance ratio $(\mathrm{C} / e)$ and Reynolds number on the turbulent heat transfer and friction in a rectangular duct $(160 \mathrm{~mm} \times 40 \mathrm{~mm})$ with ribs detached from one wall by laser holographic interferometry and pressure measurements. The range of $\mathrm{C} / e$ studied were varied from 0.25 to 1.5 and Reynolds number range was 5000-50000 for a pitch-to-rib height ratio of 10 and rib height-to-hydraulic diameter ratio of 0.08 . It was found that the friction factor in detached ribbed wall situation increased by 1.6-1.9 times over the attached ribbed wall case. It was observed that the hot spots around the concave corners behind the attached ribs $(C / e=0)$ do not occur with the detached rib wall $(C / e \neq 0)$. The average level of heat transfer enhancement increased as $\mathrm{C} / \mathrm{e}$ increased from $\mathrm{C} / \mathrm{e}=0$ to 0.38 . Beyond $C / e$ of 0.38 , the level of heat transfer enhancement decreases with increasing $C / e$. This is because of the highest forced convection resulting from the highest acceleration of the flow between the rib base and the heated wall. Detached ribbed walls resulted in the improvement of thermal performance (average heat transfer at the same pumping power) by 20-40\% compared to the attached ribbed walls.

Liou and Wang [6] presented the heat transfer and pressure drop characteristics in a developing rectangular duct with a detached square rib array and an abrupt contraction at the inlet for a Reynolds number ranging from 5000-50000. The ratios of pitch-to-rib height, rib height-to-hydraulic diameter, and detached distance-to-rib height were 10, 0.08 and 0.58. The developing flow in the detached ribbed duct was found to be hydrodynamically and thermally fully developed after the first three ribs, a result similar to that in the attached ribbed duct flows. The heat transfer augmentation by detaching a rib array a small distance of $C / e=0.58$ from the heated wall is about 1.2-1.3 and 1.1-1.4 times higher than by attaching a rib array onto the heated wall $(C / e=0)$ for the constraints of equal mass flow rate and equal pumping power. Liou et al. [7] studied the mean velocities, turbulence intensities and Reynolds stresses in a rectangular duct of a width-to-height ratio of 2 with a detached solid rib array on one wall. The Reynolds number, pitch-to-rib height ratio, and rib height-to-hydraulic diameter ratios were 20000, 10, and 0.133 . The rib-detached distance to rib height ratio was varied from 0 to 3.25 . They observed that the wake length (reattachment length), which was observed to be 3.5 times the rib height in attached rib case decreased to around 1.3 times the rib height for all clearance ratios in detached ribs cases, covered in this study. The wall jet issued from the clearance between the rib and duct wall for $\mathrm{C} / e=0.38$ generated higher convective velocity and turbulent kinetic energy. This fact provided the fluid dynamic rationale for the previously reported better heat transfer augmentation immediately behind the rib attained by the detached rib array for $C / e=0.38$.

Liou et al. [8] presented laser holographic interferometer and pressure measurements in a rectangular duct of width-to-height ratio of $4: 1$ with an array of ribs detached from one wall at a clearance-to-rib height ratio of 0.38 . The ranges of rib-to-duct height ratio, pitch-to-rib height ratio, and Reynolds number were 0.13 to $0.26,7$ to 13 and 5000 to 50000 respectively. Rib configuration of $e / B$ of 0.17 and pitch-to-rib height ratio, of 10 were found to provide the best thermal performance. Tsia and Hwang [9] conducted the study of heat transfer and friction in a rectangular duct roughened by arrays of alternate attached and detached ribs for rib-to-channel height ratio of 0.2 and rib clearanceto-height ratio of, 0.5 , respectively. Rib pitch-to-height ratios were varied from 10 to 30 . Alternate attached and detached ribbed wall configuration resulted in high heat transfer and moderate pressure drop penalty compared to fully attached ribs configuration and fully detached ribs configuration. Liou et al. [10] performed laser Doppler velocity measurements in a rotating two-pass square duct with $90^{\circ}$ ribs detached from the leading and trailing walls. The ribs were square in cross section and their detached distance/height ratio was 0.38 . The rib height/duct height ratio and pitchto-rib height ratio were 0.136 and 10 , respectively. The duct Reynolds number was varied from 10000 to 40000 and the rotation number ranged from 0 to 0.2 . The wall jet emitted from the rib-wall gap effectively removed the corner vortex prevailing in attached ribs, thus possibly improving the heat transfer deterioration immediately behind the ribs under conditions of rotation. Liou et al. [11] measured local heat transfer distribution using transient thermo chromatic liquid crystal technique and velocity field using LDV in a two pass square channel with transverse detached ribs on two walls. For this channel, the clearance ratio $(\mathrm{C} / e)$ was 0.38 , pitch-to-rib height $(P / e)$ was 10 , and rib height-to-duct height ratio was 0.136. Experiments were conducted at a constant Reynolds number of 10000 and the rotation number was varied from 0 to 0.2 . The results show the relative effect of near wall jet (in detached ribs) and the reattachment of separated flow (in the attached rib). Under conditions of rotation, span wise average over various rib heights show that the detached ribs provide more augmentation relative to attached ribs over a length of 4-rib heights behind each rib on both leading and trailing walls. However, when the entire region is covered for area averaging, it is seen that the augmentations offered by both detached and attached ribs were nearly equal. The heat transfer distribution is reported to be more uniform for detached ribs compared to attached ribs.

Johnson et al. [12] reported that gas turbine blade internal coolant passages are often oriented at an angle that is as large as $\pm 50^{\circ}-60^{\circ}$ to the axis of rotation with the angle varying widely between the midchord, leading and trailing edge regions of the rotating airfoil. The literature survey presented on detached ribs above indicates that pressure drop data is not available for varying rib pitch-to-height ratios and aspect ratio in the presence of rotation and varying channel orientation.

From the literature review, it is observed that the average heat transfer augmentation in detached ribs is marginally higher compared to attached ribs. It is seen that focus is limited to obtain heat transfer distribution for different aspect ratios and $(\mathrm{C} / \mathrm{H})$ ratios, without any pressure drop data. The 


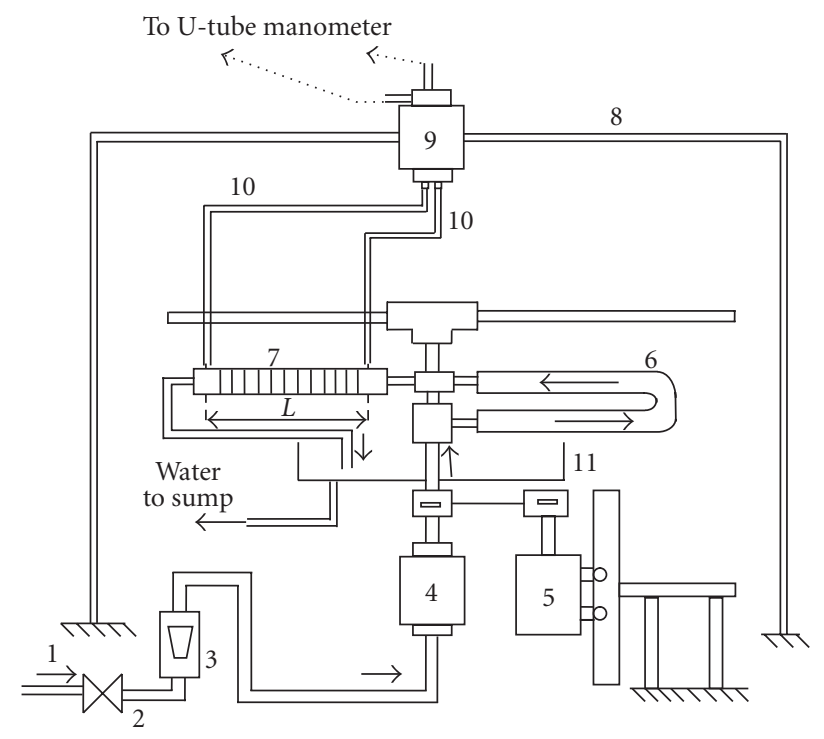

Figure 1: Experimental setup. (1) Water pumped from the sump. (2) Control valve. (3) Rotameter. (4) Bottom rotor seal. (5) D.C. Motor. (6) Developing region. (7) Test section. (8) Support frame. (9) Top rotor seal. (10) Flexible tubes connected to pressure taps. (11) Collection tank.

objective of the present work is to obtain pressure drop for detached ribs with optimum clearance ratio $(C / H=0.38)$ and compare the results with the attached rib counterpart to qualitatively evaluate the thermal performance of detached ribs.

\section{EXPERIMENTAL SETUP}

Figure 1 shows the schematic of the experimental setup used for measuring pressure drop in ribbed channels using water as working fluid. Water is pumped from the sump to the test section line through a control valve used to regulate the flow. The flow rate is measured by calibrated rotameter. Water enters the rotating hollow shaft through the rotor-seal at the bottom and passes through the developing zone pipe (on the left-hand side of the figure) and then enters the test section. The rotor-seal aids in transferring fluid from the stationary pipe to a rotating pipe/hollow shaft. The test section is so fixed to the hollow shaft that it can be rotated about its axis to obtain different orientation angle. The test section support holds the test section firmly and avoids circumferential movement of the test section while rotating. Water coming out of the test setup is collected in the stationary collection tank. A D.C. motor rotates the entire assembly through a belt drive. The speed of rotation is set by controlling the power supply to the motor through Variac. Flexible tubes are used to connect the pressure taps from the test section to the top rotor seal. The flexible tubes run through the top part of the hollow shaft and then connect to the rotor seal. The outlet port of the rotor seal is then connected to a " $U$ " tube manometer to measure the differential pressure drop.
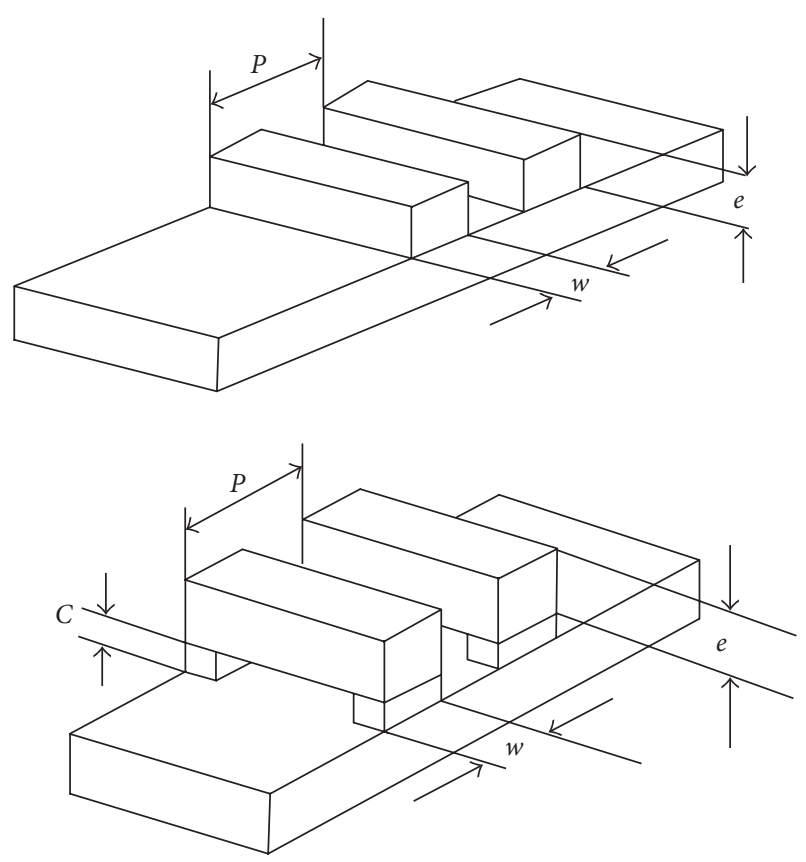

FIGURE 2: Figure showing the attached and detached rib arrangements.

The cross-sectional dimensions of square and rectangular channels are $30 \mathrm{~mm} \times 30 \mathrm{~mm}$ and $15 \mathrm{~mm} \times 30 \mathrm{~mm}$ (ribbed wall), respectively. The hydraulic diameter of the square and the rectangular channels (calculated without including the ribs) is $30 \mathrm{~mm}$ and $20 \mathrm{~mm}$ for the square channel and the rectangular channel, respectively. The test sections are fabricated by chemically bonding Plexiglas pieces machined to the desired dimensions. Ribs of $3 \mathrm{~mm} \times 3 \mathrm{~mm}$ square crosssection are used for square channel and $2 \mathrm{~mm} \times 2 \mathrm{~mm}$ for the rectangular channel. The ribs are also made of Plexiglas. Two pitch-to-rib height $(P / e)$ ratios of 5 and 10 are considered in the present study. The rib height-to-hydraulic diameter ratio $(e / D)$ is 0.1 for all the cases covered. The channel length is 30 times the hydraulic diameter for all the configurations. Ribs are fixed to the channel walls after a developing length of 15 times the hydraulic diameter of the channel for both attached and detached configurations. The mean radius of rotation is 27 times the hydraulic diameter for all the channels. For attached ribbed channels, ribs are directly fixed to the channel walls. In detached ribbed channels, ribs are fixed to the side supports of width $5 \mathrm{~mm}$. The effective flow width between the two-side supports is $20 \mathrm{~mm}$. The distance $(C)$ between the base surface and the rib corresponds to $\mathrm{C} / \mathrm{e}$ of 0.38 in square channel and 0.37 in rectangular channel. The schematic arrangement of these two configurations is shown in Figure 2. The summary of all the cases studied is given in Table 1.

Figure 3 shows the definition of the orientation angle. The test section in which the ribs are located on the trailing surface (in two-wall ribbed channels, one of the ribbed walls is on trailing surface) is considered the base case (orientation 
TABLE 1: Details of detached rib configurations covered in this study and corresponding attached rib configurations available in the literature for comparison.

\begin{tabular}{|c|c|c|c|c|c|c|}
\hline Sl no. & $C / e$ & $A R$ & Number of ribbed walls & $P / e$ & $R e$ & Ro \\
\hline 1 & 0.38 & 1 & 2 & 10,10 & $10000-17000$ & $0-0.38$ \\
\hline 2 & 0.38 & 1 & 2 & 5,5 & $10000-17000$ & $0-0.38$ \\
\hline 3 & 0.38 & 1 & 1 & 10 & $10000-17000$ & $0-0.38$ \\
\hline 4 & 0.38 & 1 & 1 & 5 & $10000-17000$ & $0-0.38$ \\
\hline 5 & 0.37 & 2 & 2 & 10,10 & $10000-17000$ & $0-0.38$ \\
\hline 6 & 0.37 & 2 & 2 & 5,5 & $10000-17000$ & $0-0.38$ \\
\hline 7 & 0.37 & 2 & 1 & 10 & $10000-17000$ & $0-0.38$ \\
\hline 8 & 0.37 & 2 & 1 & 5 & $10000-17000$ & $0-0.38$ \\
\hline 9 & 0 & 1 & 2 & 10,10 & $13000-22000$ & $0-0.36$ \\
\hline 10 & 0 & 1 & 2 & 5,5 & $13000-22000$ & $0-0.36$ \\
\hline 11 & 0 & 1 & 1 & 10 & 13800-20500 & $0-0.42$ \\
\hline 12 & 0 & 1 & 1 & 5 & 13800-20500 & $0-0.42$ \\
\hline 13 & 0 & 2 & 1 & 10 & 13800-20500 & $0-0.42$ \\
\hline 14 & 0 & 2 & 1 & 5 & 13800-20500 & $0-0.42$ \\
\hline
\end{tabular}
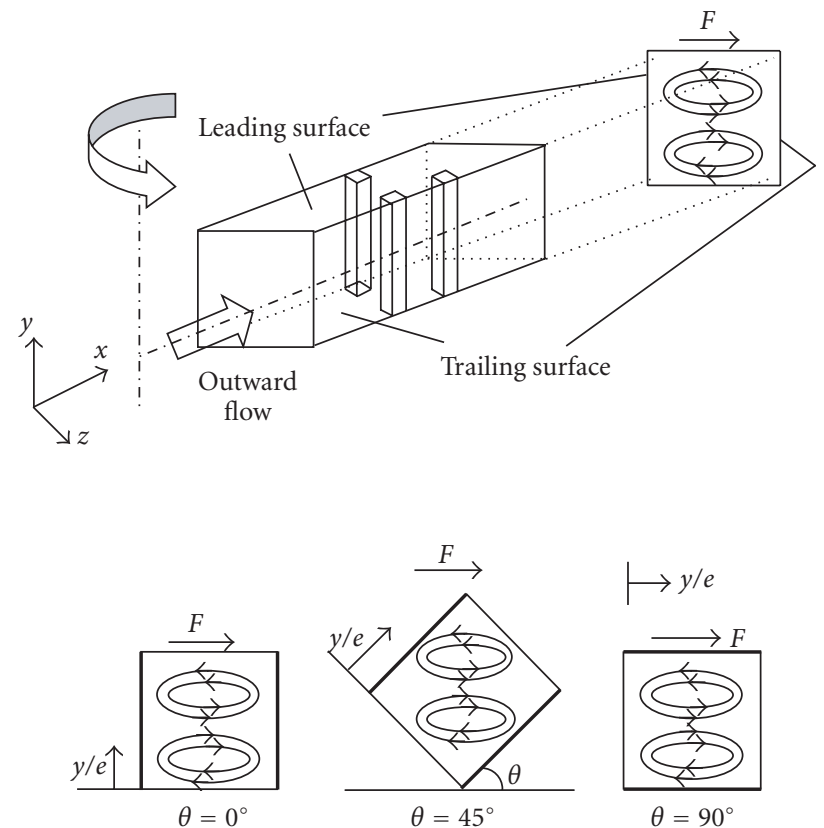

FIGURE 3: Three-dimensional sketch of the test section along with the definition of orientation angle.

angle $=0^{\circ}$ ). The direction of the Coriolis force is normal to the trailing surface and parallel to the top and bottom surfaces for the base case. Other orientation angles are obtained by turning the channel about its axis with reference to the base case. A stationary U-tube differential manometer is used to measure the pressure drop in the rotating test section with carbon tetrachloride as the manometer fluid. The pressure transfer between the taps on the rotating test section and the stationary manometer is achieved through a specially fabricated pressure transfer device using two commercially available rotor seals.

\section{DATA REDUCTION}

The arithmetic average of the pressure drop between the two pressure taps on each of the four walls (trailing surface, leading surface, top surface, and bottom surface) is used for estimating the overall pressure drop. Two pressure taps are set on all the walls at a distance of one pitch upstream of the first rib and one pitch downstream of the last rib to obtain the pressure drop.

The resulting average like this was found to be identical to the pressure drop measured by physically interconnecting the four pressures taps at a given location. This overall pressure drop is used to calculate the friction factor given by

$$
f=\frac{\Delta P}{(1 / 2) \rho V^{2}(4(L / D))} .
$$

The length " $L$ " used in the above expression is the distance between the two pressure taps stated above and " $D$ " is the hydraulic diameter of the channel. The length " $L$ " is 12 and 7 times the hydraulic diameter of the channel for $P / e=10$ and 5 cases, respectively. This corresponds to the total number of ribs, 10, in both pitch-to-rib height ratio of 5 and 10 cases. The maximum uncertainty in the average friction factor is about $6 \%$ by the uncertainty estimation method of Kline and McClintock [13] at a 95\% confidence level. The average friction factor is normalized by the friction factor for 
fully developed turbulent flow in smooth circular tubes proposed by Blasius as given by

$$
f_{0}=0.046 R e^{-0.2} \quad \text { for } 10000 \leq R e \leq 100000 .
$$

\section{RESULTS AND DISCUSSIONS}

\subsection{Detached ribs on one wall}

Figure 4 shows the friction factor variation for pitch-to-rib height ratios of 5 and 10 with detached ribs on one wall in a square channel. Experiments are conducted for a Reynolds number ranging from 10000 to 17000 and rotation number ranging from 0 to 0.38 . The orientation angle is varied from $0^{\circ}$ to $180^{\circ}$ in steps of $30^{\circ}$. It is observed that the friction factor ratio is independent of orientation angle at all Reynolds numbers and it is greater for pitch to rib height ratio of 10 compared to that of 5 under stationary conditions. Under rotating condition, the friction factor ratio increases consistently with the increase in the orientation angle from $0^{\circ}$ to $90^{\circ}$ and decreases with the increase of orientation angle from $90^{\circ}-180^{\circ}$ at a given Reynolds number and rotation number for both pitch-to-rib height ratios. Increase in the friction factor ratio for pitch-to-rib height ratio of 5 is higher compared to that of 10. It can be seen that the friction factor ratio for pitch-to-rib height ratio of 5 is higher compared to that of pitch-to-rib height ratio 10 at all orientation angles except at $0^{\circ}$ and $180^{\circ}$. These trends of friction factor variation with orientation angle are similar to the corresponding attached rib configuration as reported by Sardeshpande et al. [14] as shown in Figure 5 which shows the friction factor variations for pitch-to-rib height ratios of 5 and 10 with attached ribs on one wall in a square channel. Figure 6 shows the comparison of friction factors for both attached and detached configurations at Reynolds number of 17000, Rotation number 0.22 for detached ribs, and Reynolds number of 17200 , rotation number 0.2 for attached ribs. It can be observed that the friction factor ratio of detached ribs is higher compared to those of attached ribs under stationary condition for both the pitch-to-rib height ratios of 5 and 10 (for $P / e=10, f / f_{0}$ of detached ribs is $56 \%$ and for $P / e=5,69 \%$ higher compared to those of attached ribs) at a given Reynolds number. Under conditions of rotation, the friction factor, a ratio of detached ribs is higher compared to the corresponding attached ribs for pitch-to-rib height ratio of 10 . However, for pitch to rib height ratio of 5 , the friction factor ratio of detached ribs are comparable with that of attached ribs.

Pressure drop measurements are made with a rectangular channel of aspect ratio 2 to study the effect of aspect ratio. Figure 7 shows the effect of orientation angle on the friction factor ratio for pitch-to-rib height ratios of 5 and 10 with detached ribs on one wall. Trends of friction factor ratio variations with rotation number and orientation angle are similar to that observed in a square channel. It can be observed that the friction factor ratios of rectangular channel are lower than that of square channel for both pitch-to-rib height ratios of 5 and 10 at the same Reynolds number under stationary conditions. The increase in the friction factor ratio with
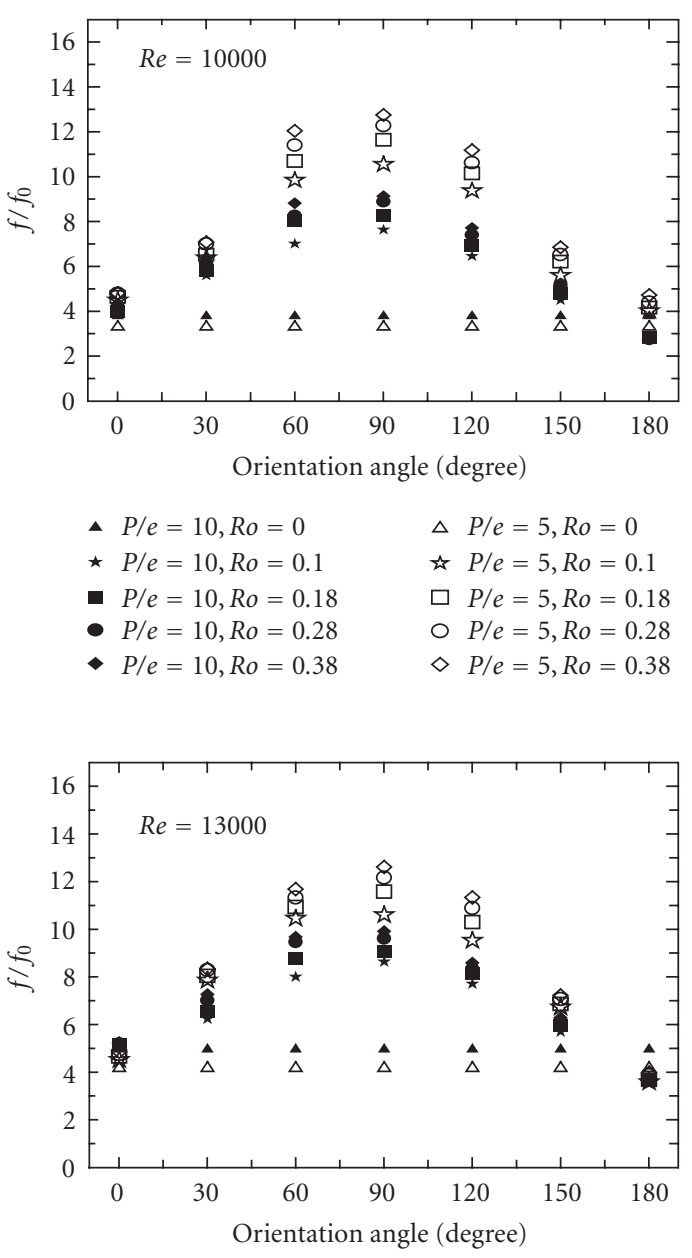

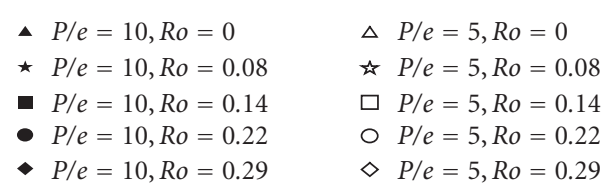

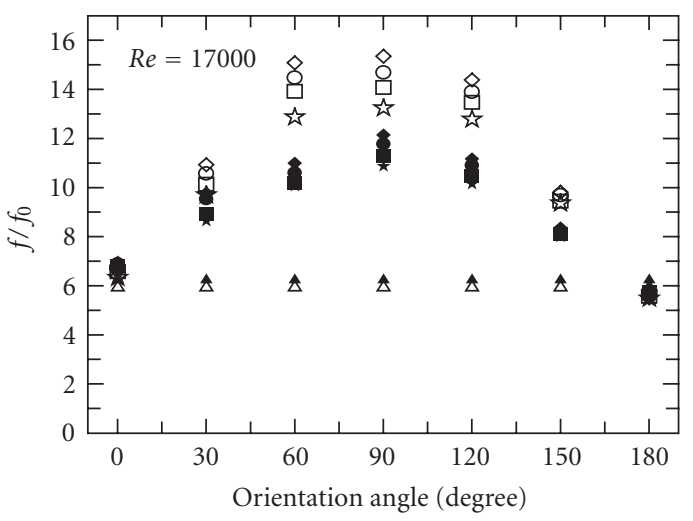

- $P / e=10, R o=0$

$\triangle P / e=5, R o=0$

$\star P / e=10, R o=0.06$

- $P / e=10, R o=0.11$

« $P / e=5, R o=0.06$

- $P / e=10, R o=0.17$

$\square P / e=5, R o=0.11$

- $P / e=10, R o=0.22$

○ $P / e=5, R o=0.17$

$\diamond P / e=5, R o=0.22$

FIGURE 4: Effect of orientation angle in a rib-roughened square channel with detached ribs on one wall. 


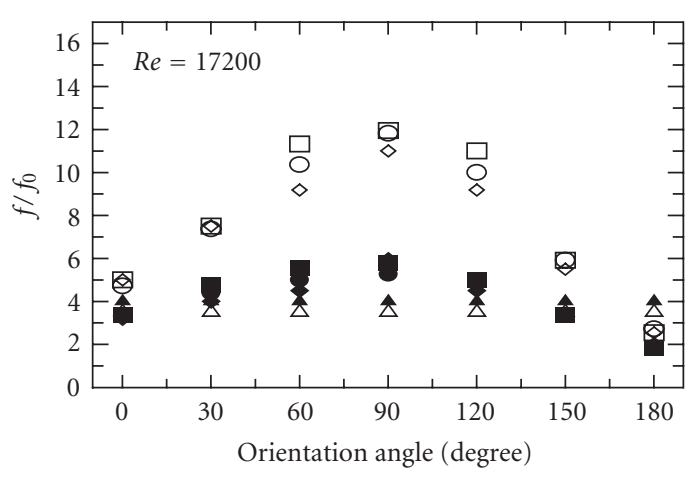
- $P / e=10, R o=0$
- $P / e=10, R o=0.2$
- $P / e=10, R o=0.27$
$\triangle P / e=5, R o=0$
$\diamond P / e=5, R o=0.2$
- $P / e=10, R o=0.34$
$\mathrm{P} / \mathrm{e}=5, \mathrm{Ro}=0.27$
$\square P / e=5, R o=0.34$

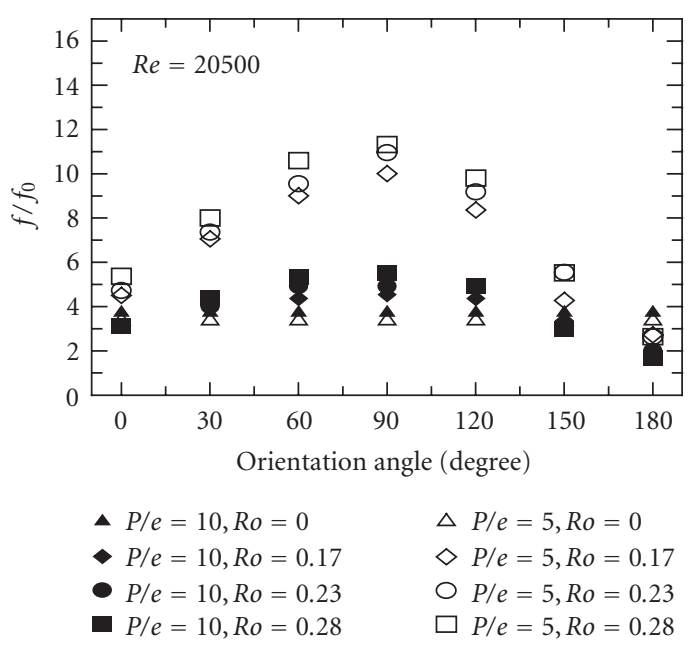

FIgURE 5: Effect of orientation angle in a rib-roughened square channel with attached ribs on one wall (for comparison from Sardeshpande et al. [14]).

the increase in Reynolds number is less in rectangular channel ( $10 \%$ increase from $R e=10000$ to 17000$)$ compared to that of square channel (65-80\% increase from $R e=10000$ to 17000 ) under both stationary and rotating conditions. Increase in the friction factor ratio with the orientation angle for a given Reynolds number and rotation number is lower for rectangular channel compared to square channel (at a Reynolds number of 10000 , rotation number of 0.38 , and orientation angle of $90^{\circ}$, the increase in friction factor ratio is $180 \%$ and $100 \%$ for pitch-to-rib height ratios of 5 and 10 in rectangular channel and $240 \%$ and $150 \%$ for pitch-to-rib height ratios of 5 and 10 in square channel).

The trends of friction factor ratios in detached ribbed rectangular channel are similar to that observed in corresponding attached rib configuration as reported by Sardeshpande et al. [14] as shown in Figure 8 which shows the effect

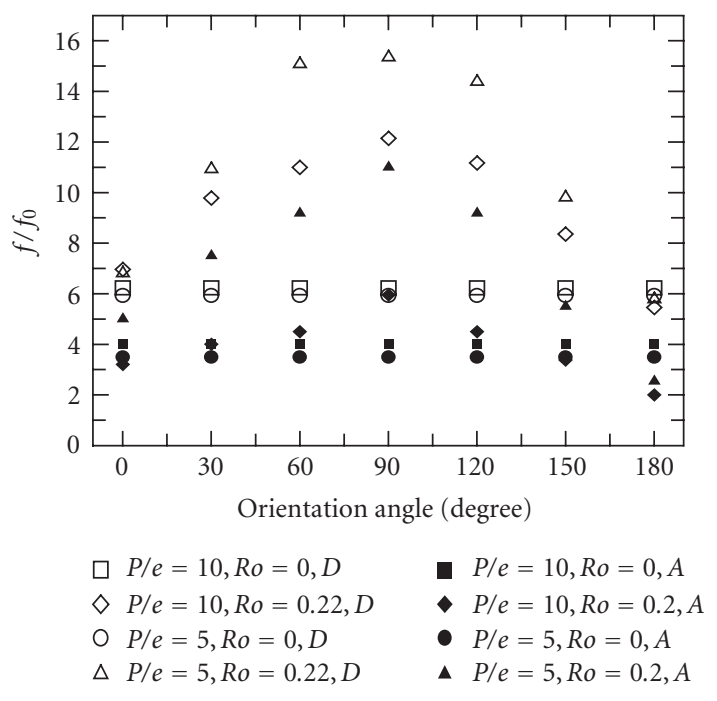

Figure 6: Comparison of friction factor ratios in square channels with detached (D) and attached (A) rib configurations (for detached ribs, $R e=17000$ and for attached ribs, $R e=17200)$.

of orientation angle, rotation number, and Reynolds number on the friction factor ratio in attached ribbed rectangular channel. The friction factor ratios of detached ribs are lower than that of attached ribs both under stationary and rotating conditions for both the pitch-to-rib height ratios as observed in square channels.

\subsection{Ribs on two opposite walls}

Figure 9 shows the friction factor variation for pitch-to-rib height ratios of 5 and 10 with detached ribs on two opposite walls. The orientation angle is varied from $0^{\circ}-90^{\circ}$ in steps of $30^{\circ}$ due to symmetry of the channel. The effects of orientation angle and pitch-to-rib height ratio are similar to that observed in one wall ribbed channel under conditions of rotation. Figure 10 compares the friction factor in a square channel with detached ribs on one wall and two walls under stationary and rotation conditions at a Reynolds number 17000. It can be seen that, under both stationary and rotating conditions, the friction factor ratio of two-wall detached ribbed channel is around 1.9-2.4 times the corresponding one-wall detached ribbed channel for both pitch-to-rib height ratios. Figure 11 shows the friction factor variation for pitch-to-rib height ratios of 5 and 10 with attached ribs on two opposite walls presented by Prabhu et al. [15]. Figure 12 shows the comparison of friction factor for attached and detached ribs at Reynolds number 17000 and rotation number $0,0.22$ for pitch-to-rib height ratio of 5 and 10. It is observed that friction factor ratio for detached ribs is higher compared to the corresponding attached rib configuration under stationary and rotation condition. The difference in friction factor between the detached ribs and attached ribs increases with the increase in orientation angle. 


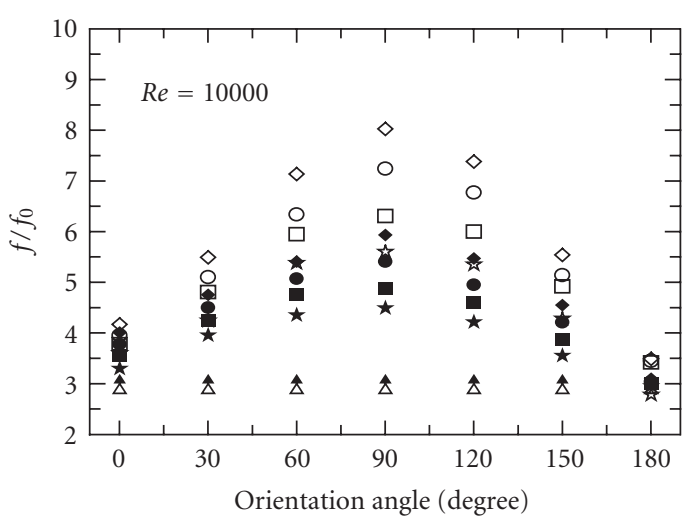
$\triangle P / e=5, R o=0$
* $P / e=5, R o=0.1$
$\square P / e=5, R o=0.18$
○ $P / e=5, R o=0.28$
$\diamond P / e=5, R o=0.38$
- $P / e=10, R o=0$
$\star P / e=10, R o=0.1$
- $P / e=10, R o=0.18$
- $P / e=10, R o=0.28$
- $P / e=10, R o=0.38$

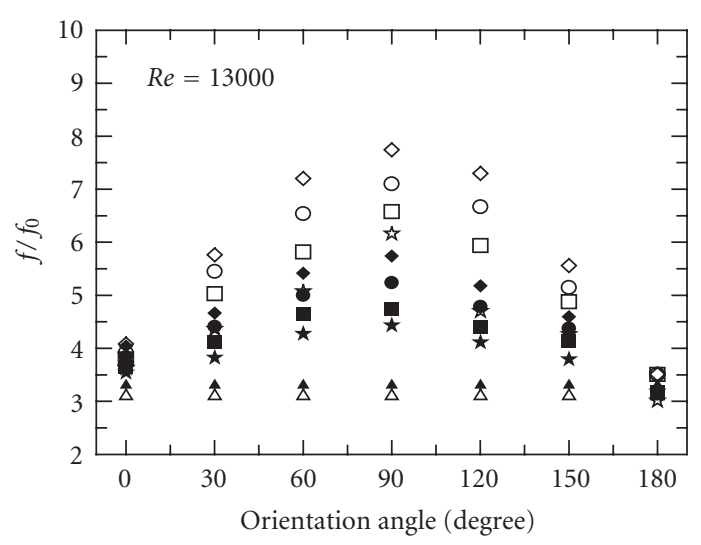
$\triangle P / e=5, R o=0$
* $P / e=5, R o=0.08$
- $P / e=10, R o=0$
$\square P / e=5, R o=0.14$
○ $P / e=5, R o=0.22$
$\star P / e=10, R o=0.08$
$\diamond P / e=5, R o=0.29$
- $P / e=10, R o=0.14$
- $P / e=10, R o=0.22$
- $P / e=10, R o=0.29$

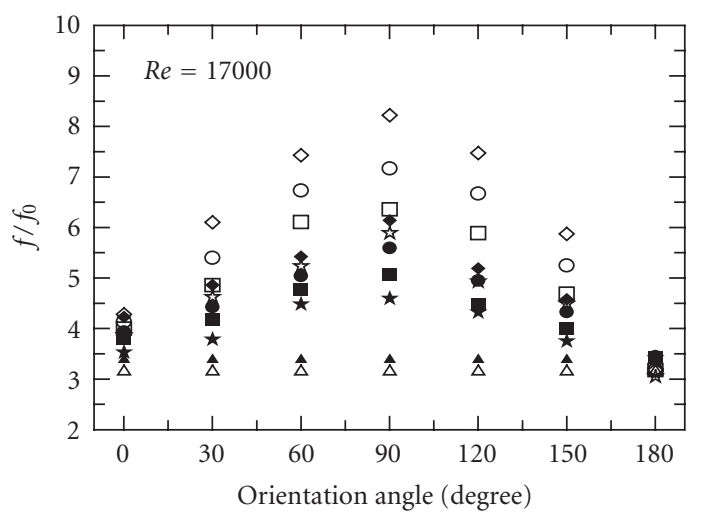
$\triangle P / e=5, R o=0$
- $P / e=10, R o=0$
\ $P / e=5, R o=0.06$
$\star P / e=10, R o=0.06$
$\square P / e=5, R o=0.11$
- $P / e=10, R o=0.11$
○ $P / e=5, R o=0.17$
$\diamond P / e=5, R o=0.22$
- $P / e=10, R o=0.17$
- $P / e=10, R o=0.22$

FIGURE 7: Effect of orientation angle in a rib-roughened rectangular channel with detached ribs on one wall.

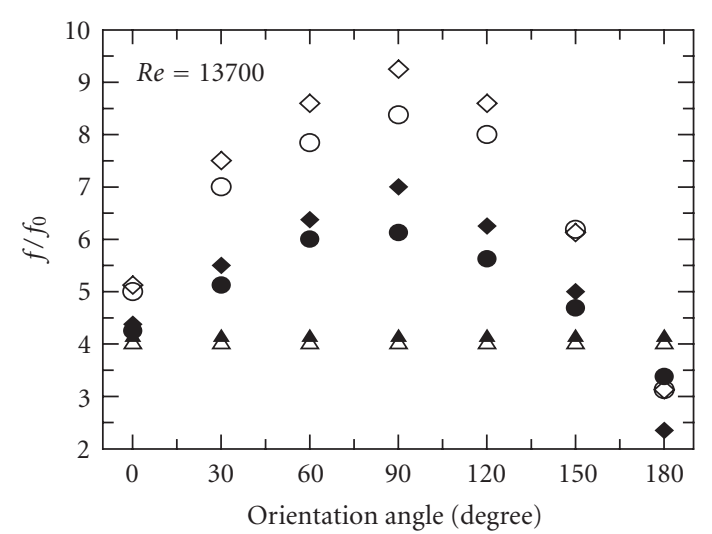
- $P / e=10, R o=0$
$\triangle P / e=5, R o=0$
- $P / e=10, R o=0.15$
$\mathrm{P} / \mathrm{e}=5, \mathrm{Ro}=0.15$
- $P / e=10, R o=0.19$
$\diamond P / e=5, R o=0.19$

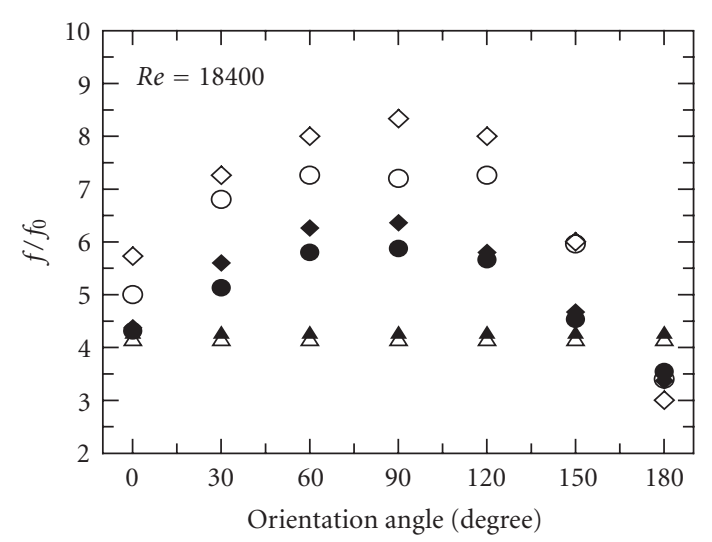
- $P / e=10, R o=0$
$\triangle P / e=5, R o=0$
- $P / e=10, R o=0.11$
$\bigcirc P / e=5, R o=0.11$
- $P / e=10, R o=0.14$
$\diamond P / e=5, R o=0.14$

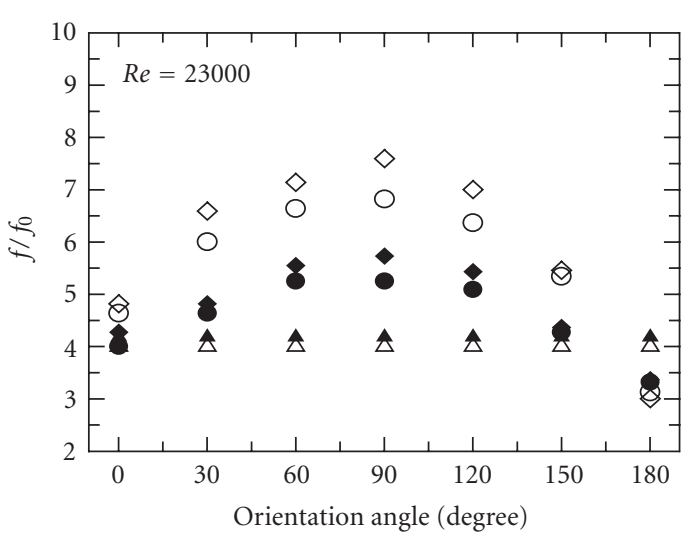
- $P / e=10, R o=0$
$\triangle P / e=10, R o=0$
- $P / e=10, R o=0.09$
$P / e=5, R o=0.09$
- $P / e=5, R o=0.11$
$\diamond P / e=5, R o=0.11$

FIGURE 8: Effect of orientation angle in a rib-roughened rectangular channel with attached ribs on one wall (for comparison from Sardeshpande et al. [14]). 


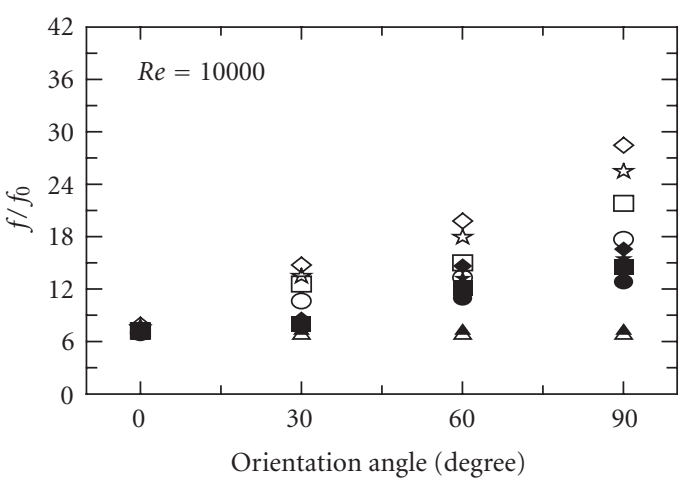

- $P / e=10,10, R o=0$

$\triangle P / e=5,5, R o=0$

- $P / e=10,10, R o=0.1$

$P / e=5,5, R o=0.1$

- $P / e=10,10, R o=0.19$

$\star P / e=10,10, R o=0.29$

- $P / e=10,10, R o=0.38$

$P / e=5,5, R o=0.19$

¿ $P / e=5,5, R o=0.29$

$\diamond P / e=5,5, R o=0.38$

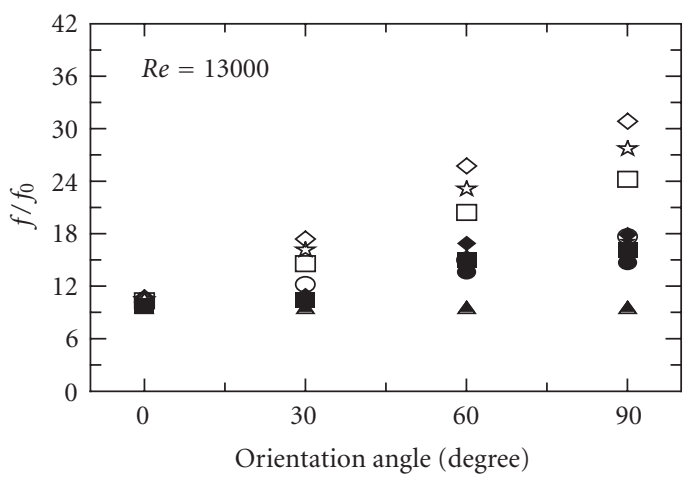

- $P / e=10,10, R o=0$

- $P / e=10,10, R o=0.08$

- $P / e=10,10, R o=0.14$

$\star P / e=10,10, R o=0.22$

- $P / e=10,10, R o=0.29$

$\triangle P / e=5,5, R o=0$

P $/ e=5,5, R o=0.08$

$\square P / e=5,5, R o=0.14$

就 $P / e=5,5, R o=0.22$

$\diamond P / e=5,5, R o=0.29$

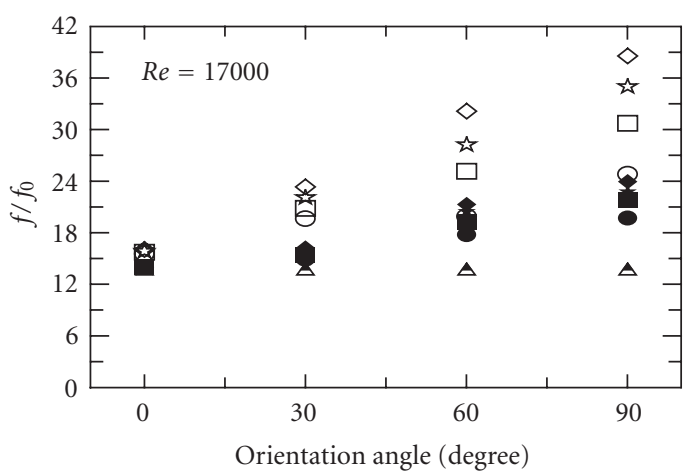

- $P / e=10,10, R o=0$

$\triangle P / e=5,5, R o=0$

- $P / e=10,10, R o=0.06$

- $P / e=10,10, R o=0.11$

○ $P / e=5,5, R o=0.06$

$\square P / e=5,5, R o=0.11$

$\star P / e=10,10, R o=0.17$

¿ $P / e=5,5, R o=0.17$

- $P / e=10,10, R o=0.22$

$\diamond P / e=5,5, R o=0.22$

FIGURE 9: Effect of orientation angle in a rib-roughened square channel with detached ribs on two opposite walls.

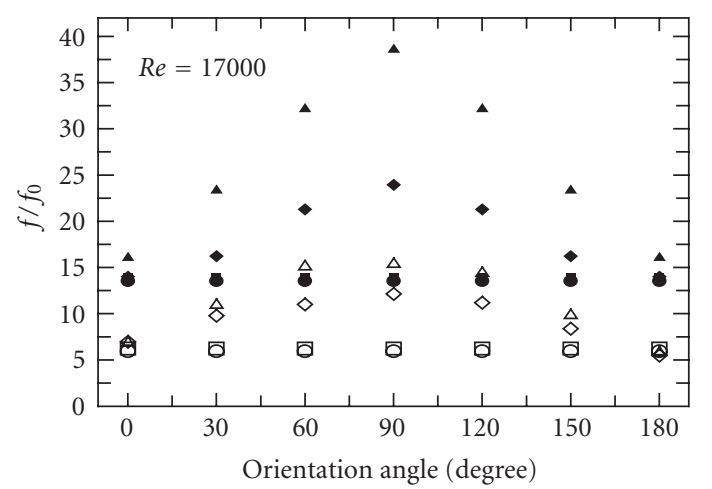

$$
\begin{array}{ll}
\square P / e=10, R o=0,1 w & \text { - } P / e=10, R o=0,2 w \\
\diamond P / e=10, R o=0.22,1 w & \bullet P / e=10, R o=0.22,2 w \\
\circ P / e=5, R o=0,1 w & \bullet P / e=5, R o=0,2 w \\
\triangle P / e=5, R o=0.22,1 w & \triangle P / e=5, R o=0.22,2 w
\end{array}
$$

FIGURE 10: Comparison of friction factor ratios in square channel with detached ribs on one wall and two walls at $R e=17000$.

Figure 13 shows the effect of orientation, rotation number, and Reynolds number on the friction factor ratio in a rectangular channel with detached ribs on two opposing walls. Unlike the square channel, friction factor ratios of twowall detached ribbed rectangular channel are not twice that of one-wall detached ribbed rectangular channel. However, the ratio of friction factor of two-wall detached ribbed channel to one-wall detached ribbed channel is increasing with the increase in Reynolds number (i.e., 2.2 times at $R e=$ $10000,3.1$ times at $R e=13000$, and 4.1 times at $R e=17000)$. Similarly, under conditions of rotation, for both the pitchto-rib height ratios of 5 and 10, the ratio of friction factor of two-wall detached ribbed channel to one-wall detached ribbed channel is increasing with the increase in Reynolds number for a given orientation angle. Friction factor ratios of two-wall detached ribbed rectangular channel are comparable with those of two-wall detached ribbed square channel. Unlike single-wall detached ribbed channels, the effect of aspect ratio is minimal in two-wall detached ribbed channel.

Figure 14 shows the variation of ratio of pressure drop on individual wall to overall pressure drop (mean of pressure drop on all four walls) for two-wall detached rib square channel at Reynolds number 17000 and rotation number 0.22. The pressure side, suction side, top side, and bottom side correspond to $0^{\circ}$ orientation. It is observed that, at $0^{\circ}$ orientation, the pressure drop on the trailing side increases due to the action of Coriolis force on this face during rotation where as on the suction side, the pressure drop decreases. Pressure drop on the top and bottom sides remains the same. However, when the channel is rotated to $30^{\circ}, 60^{\circ}$, and $90^{\circ}$ the top side becomes the pressure side and bottom side becomes the suction side. The two ribbed walls (pressure and suction surface at $0^{\circ}$ orientation) become top and bottom side. Due to the changing orientation at $30^{\circ}$ and $60^{\circ}$, the Coriolis force acts on part of the pressure side and the top side leading to 


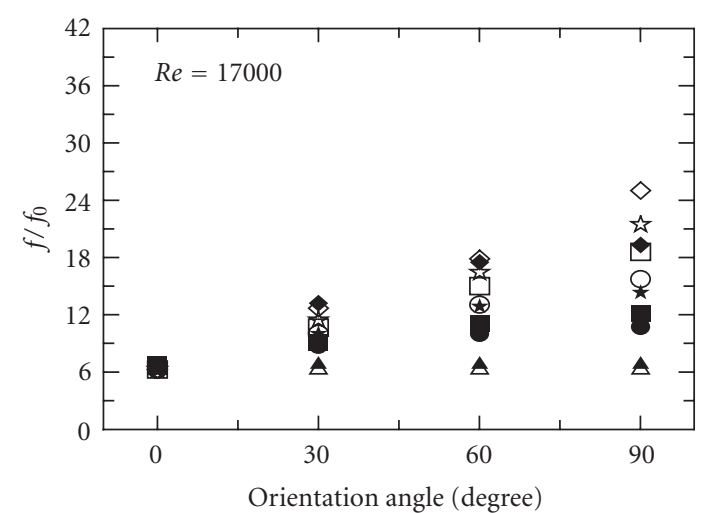

$$
\begin{aligned}
& \text { \ } P / e=10,10, R o=0 \quad \Delta P / e=5,5, R o=0 \\
& \text { - } P / e=10,10, R o=0.11 \quad \bigcirc P / e=5,5, R o=0.11 \\
& \text { - } P / e=10,10, R o=0.17 \quad \square P / e=5,5, R o=0.17 \\
& \star P / e=10,10, R o=0.23 \text { और } P / e=5,5, R o=0.23 \\
& \text { ४P/e }=10,10, R o=0.38 \quad \diamond P / e=5,5, R o=0.38
\end{aligned}
$$

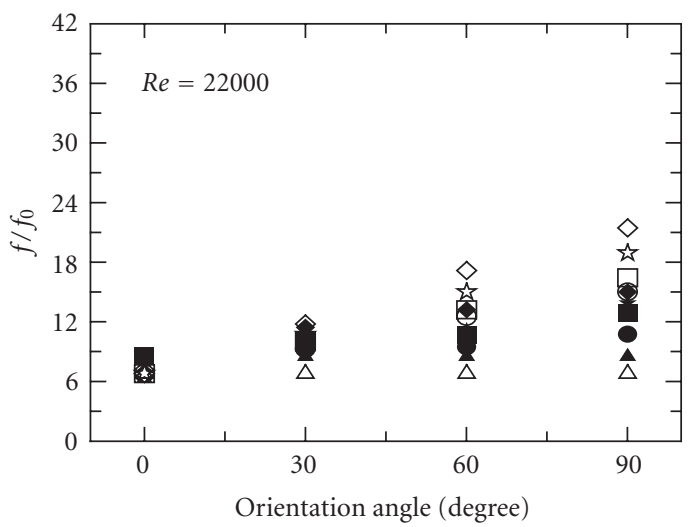

$$
\begin{aligned}
& \text { \ } P / e=10,10, R o=0 \quad \Delta P / e=5,5, R o=0 \\
& \text { - } P / e=10,10, R o=0.09 \quad \bigcirc P / e=5,5, R o=0.09 \\
& \text { - } P / e=10,10, R o=0.13 \quad \square P / e=5,5, R o=0.13 \\
& \star P / e=10,10, R o=0.18 \quad \star \quad P / e=5,5, R o=0.18 \\
& \text { ४ } P / e=10,10, R o=0.27 \quad \diamond P / e=5,5, R o=0.27
\end{aligned}
$$

FIGURE 11: Effect of orientation angle in a rib-roughened square channel with attached ribs on two opposite walls (for comparison from Prabhu et al. [15]).

increase in the pressure drop on the top side. However, on the bottom side, the pressure drop decreases as it moves towards the suction side.

\section{CONCLUSIONS}

An experimental study has been conducted to investigate the effect of Reynolds number, rotation number, orientation angle, aspect ratio, pitch-to-rib height ratio and number of ribbed surfaces on the pressure drop distribution in detached ribbed channels. Friction factor ratios of detached ribbed channels are compared with that of attached ribbed channels

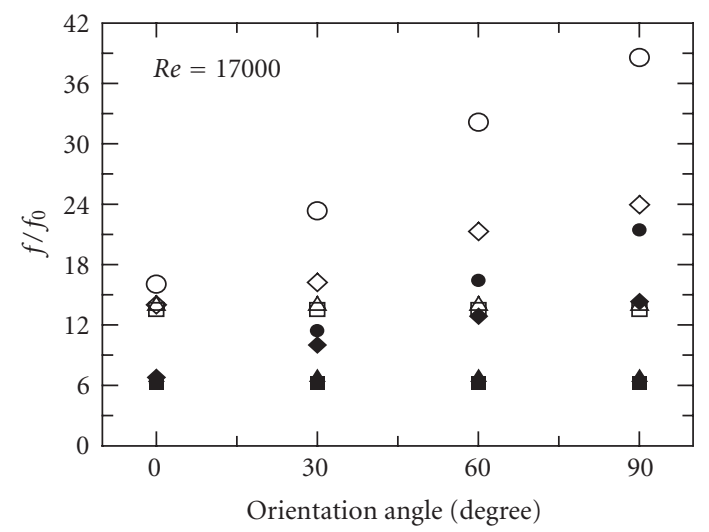

$$
\begin{array}{ll}
\triangle P / e=10,10, R o=0(D) & \Delta P / e=10,10, R o=0(A) \\
\diamond P / e=10,10, R o=0.22(D) & \bullet P / e=10,10, R o=0.22(A) \\
\square P / e=5,5, R o=0(D) & \square P / e=5,5, R o=0(A) \\
\bigcirc P / e=5,5, R o=0.22(D) & \bullet P / e=5,5, R o=0.22(A)
\end{array}
$$

FIGURE 12: Comparison of friction factor in square channels with detached (D) and attached (A) rib configurations at $R e=17000$.

available in the literature. Following are the conclusions that may be drawn from the present study.

(i) Friction factor ratio of detached ribs is higher compared to that of attached ribs in stationary single-wall ribbed square channel for both the pitch-to-rib height ratios of 5 and 10 at a given Reynolds number. Under conditions of rotation, the friction factor ratios of detached ribs are higher compared to those of attached ribs for pitch-to-rib height ratio of 10 and comparable to each other for a pitch-to-rib height ratio of 5. However, in rectangular single-wall ribbed channel, the friction factor ratios of detached ribs are less than that of attached ribs both under stationary and rotating conditions for both the pitch-to-rib height ratios.

(ii) In two-wall ribbed square channel, the friction factor ratio in detached ribs is higher compared to the corresponding attached rib configuration under both stationary and rotating conditions and the difference in friction factor between the detached ribs and attached ribs increases with the increase in Reynolds number.

(iii) In square channels with detached ribs, friction factor ratio for two-wall ribbed is around twice that of singlewall ribbed under both stationary and rotating conditions. However, in rectangular channel, the ratio of friction factor of two-wall detached ribbed channel to single-wall detached ribbed channel increases with the increase in Reynolds number.

(iv) Irrespective of pitch-to-rib height ratios (5 and 10) and aspect ratio (square and rectangular channels), friction factor ratio in single-wall detached ribbed channel increases with the increase in the orientation angle from $0^{\circ}-90^{\circ}$ and decreases with the increase of orientation angle from $90^{\circ}-$ $180^{\circ}$ for a given Reynolds number and rotation number. Under conditions of rotation, the effect of rotation number is more pronounced for an orientation angle of $90^{\circ}$ at a given 


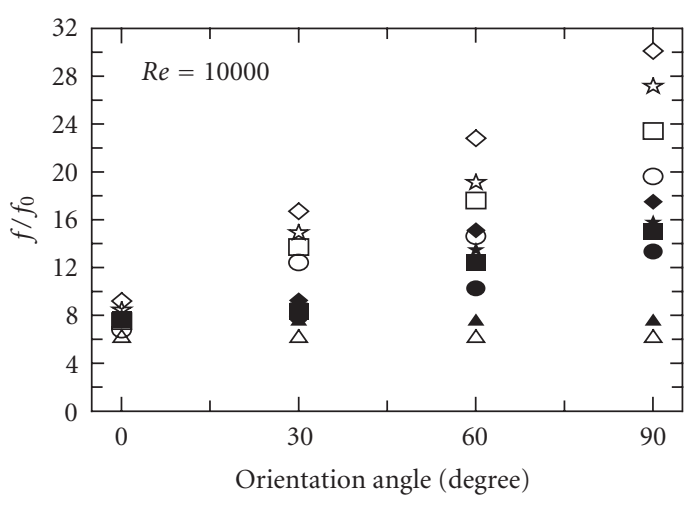
$\triangle P / e=5,5, R o=0$
$\bigcirc P / e=5,5, R o=0.1$
$\square P / e=5,5, R o=0.19$
¿ $P / e=5,5, R o=0.29$
$\diamond P / e=5,5, R o=0.38$
\ $P / e=10,10, R o=0$
- $P / e=10,10, R o=0.1$
- $P / e=10,10, R o=0.19$
$\star P / e=10,10, R o=0.29$
- $P / e=10,10, R o=0.38$

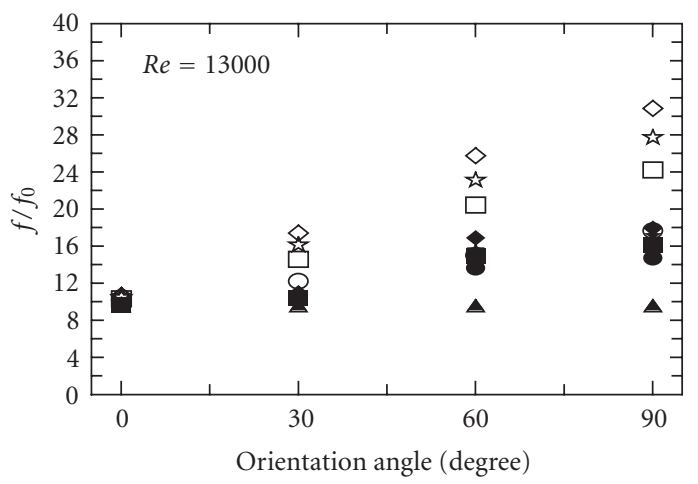
- $P / e=10,10, R o=0$
- $P / e=10,10, R o=0.08$
- $P / e=10,10, R o=0.14$
$\star P / e=10,10, R o=0.22$
- $P / e=10,10, R o=0.29$
$\triangle P / e=5,5, R o=0$
$\bigcirc P / e=5,5, R o=0.08$
$\square P / e=5,5, R o=0.14$
论 $P / e=5,5, R o=0.22$
$\diamond P / e=5,5, R o=0.29$

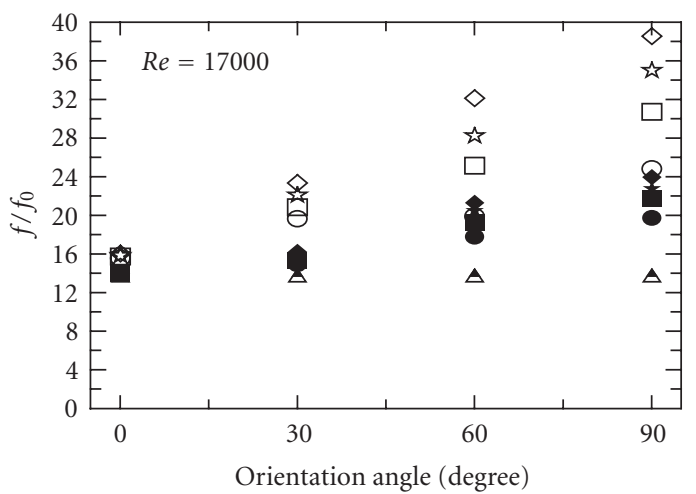
- $P / e=10,10, R o=0$
- $P / e=10,10, R o=0.06$
$\triangle P / e=5,5, R o=0$
- $P / e=10,10, R o=0.11$
$\star P / e=10,10, R o=0.17$
- $P / e=10,10, R o=0.22$
$\mathrm{P} / \mathrm{e}=5,5, R o=0.06$
$\square P / e=5,5, R o=0.11$
L $P / e=5,5, R o=0.17$
$\diamond P / e=5,5, R o=0.22$

FIGURE 13: Effect of orientation angle in a rib-roughened rectangular channel with detached ribs on two opposite walls.

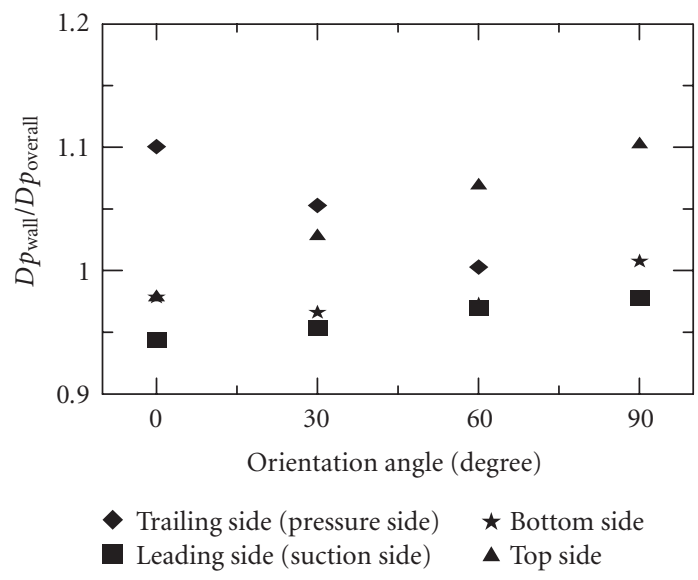

FIGURE 14: Variation of pressure drop on individual wall as a fraction of overall pressure drop for two-wall detached ribbed square channel at $R e=17000$ and $R o=0.22$.

Reynolds number for single-wall detached ribbed channel and two-wall detached ribbed channel.

(v) Under conditions of rotation, friction factor ratios of pitch-to-rib height ratio of 5 are greater than those of pitchto-rib height ratio of 10 for orientation angles $30^{\circ}-90^{\circ}$ in two-wall detached ribbed channel and $30^{\circ}$ to $150^{\circ}$ in singlewall detached ribbed channel.

(vi) In single-wall detached ribbed channel, increase in the friction factor ratio with the orientation angle is lower for rectangular channel compared to that of square channel for both the pitch-to-rib height ratios at a given Reynolds number and rotation number.

(vii) Friction factor ratios of two-wall detached ribbed rectangular channel are comparable with those of two-wall detached ribbed square channel both under stationary and rotating conditions.

It is observed in the literature that the augmentations offered by both detached and attached ribs are nearly equal. However, the heat transfer distribution between detached ribs is more uniform compared to that between attached ribs. In the present investigation, general observation is that the friction factors caused by detached ribs are greater compared to those of attached ribs. Hence, thermal performance under constant pumping power of detached ribs may not be better than attached ribs. However, this has to be confirmed through further experimental/numerical investigations.

\section{Nomenclature}

$A R \quad$ Aspect ratio (ribbed side width/channel height)

$B \quad$ Height of the channel (m)

C Detachment gap height $(\mathrm{m})$

$D \quad$ Hydraulic diameter $(\mathrm{m})$

$D p_{\text {wall }}$ Pressure difference between the two pressure taps on the same wall $(\mathrm{N})$

$D p_{\text {over }}$ Average of the pressure drop on all walls $(\mathrm{N})$ 
e Rib height $(\mathrm{m})$

$F$ Coriolis force (N)

$f$ Friction factor for the ribbed channel

$f_{0}$ Friction factor for fully developed smooth channel flow

$H$ Channel height ( $\mathrm{m})$

$L$ Distance between which the static pressure difference is measured $(\mathrm{m})$

$P \quad$ Rib pitch $(\mathrm{m})$

$P_{2}$ Static pressure at a distance of one pitch downstream of the last rib $(\mathrm{Pa})$

$P_{1}$ Static pressure at a distance of one pitch upstream of the first rib $(\mathrm{Pa})$

Re Reynolds number $(\rho V D / \mu)$

Ro Rotation number $(\omega D / V)$

$V$ Average velocity in a flow channel $(\mathrm{m} / \mathrm{s})$

$W$ Channel width (m)

$w$ Rib width (m)

$\rho$ Density of water $\left(\mathrm{kg} / \mathrm{m}^{3}\right)$

$\mu$ Dynamic viscosity of water (Pa.s)

$\omega$ Rotational speed ( $\mathrm{rad} / \mathrm{s})$

$\theta$ Orientation angle (deg)

\section{REFERENCES}

[1] H. Fujita, H. Takahama, and R. Yamashita, "Forced convection heat transfer on a plate with a cylinder inserted in the boundary layer," Heat Transfer-Japanese Research, vol. 7, no. 4, pp. 69-78, 1978.

[2] Y. Kawaguchi, K. Suzuki, and T. Sato, "Heat transfer promotion with a cylinder array located near the wall," International Journal of Heat and Fluid Flow, vol. 6, no. 4, pp. 249-255, 1985.

[3] K. Oyakawa, T. Shinzato, and I. Mabuchi, "Effect on heat transfer augmentation of some geometric shapes of a turbulence promoter in a rectangular duct," Bulletin of the Japan Society of Mechanical Engineers, vol. 29, no. 256, pp. 3415-3420, 1986.

[4] M. Yao, M. Nakatani, and K. Suzuki, "Flow visualization and heat transfer experiments in a duct with a staggered array of cylinders," Experimental Thermal and Fluid Science, vol. 2, no. 2, pp. 193-200, 1989.

[5] T.-M. Liou, W.-B. Wang, and Y.-J. Chang, "Holographic interferometry study of spatially periodic heat transfer in a channel with ribs detached from one wall," Transactions of the ASME, Journal of Heat Transfer, vol. 117, no. 1, pp. 32-39, 1995.

[6] T.-M. Liou and W.-B. Wang, "Laser holographic interferometry study of developing heat transfer in a duct with a detached rib array," International Journal of Heat and Mass Transfer, vol. 38, no. 1, pp. 91-100, 1995.

[7] T.-M. Liou, C.-P. Yang, and H.-L. Lee, "LDV measurements of spatially periodic flows over a detached solid-rib array," Transactions of the ASME, Journal of Fluids Engineering, vol. 119, no. 2, pp. 383-389, 1997.

[8] T.-M. Liou, W.-J. Shuy, and Y.-H. Tsao, "Effect of rib height and pitch on the thermal performance of a passage disturbed by detached solid ribs," Transactions of the ASME, Journal of Turbomachinery, vol. 120, no. 3, pp. 581-588, 1998.

[9] J. P. Tsia and J. J. Hwang, "Measurements of heat transfer and fluid flow in a rectangular duct with alternate attached- detached rib-arrays," International Journal of Heat and Mass Transfer, vol. 42, no. 11, pp. 2071-2083, 1998.

[10] T.-M. Liou, M.-Y. Chen, and K.-H. Chang, "Spectrum analysis of fluid flow in a rotating two-pass duct with detached $90^{\circ}$ ribs," Experimental Thermal and Fluid Science, vol. 27, no. 3, pp. 313-321, 2003.

[11] T.-M. Liou, M.-Y. Chen, and Y.-M. Wang, "Heat transfer, fluid flow, and pressure measurements inside a rotating two-pass duct with detached 90-deg ribs," Transactions of the ASME, Journal of Turbomachinery, vol. 125, no. 3, pp. 565-574, 2003.

[12] B. V. Johnson, J. H. Wagner, G. D. Steuber, and F. C. Yeh, "Heat transfer in rotating serpentine passages with selected model orientations for smooth or skewed trip walls," Transactions of the ASME, Journal of Turbomachinery, vol. 116, no. 4, pp. 738744, 1994.

[13] S. J. Kline and F. A. McClintock, "Describing uncertainties in single-sample experiments," Mechanical Engineering, vol. 75, pp. 3-8, 1953.

[14] V. D. Sardeshpande, K. Arun, S. V. Prabhu, and R. P. Vedula, "Effect of aspect ratio, channel orientation and rib pitch to height ratio on pressure drop characteristics in a rotating channel with ribs on one wall," in Proceedings of the 43rd AIAA Aerospace Sciences Meeting and Exhibit, Reno, Nev, USA, January 2005, AIAA-2005-577.

[15] S. V. Prabhu, N. Arora, and R. P. Vedula, "Effect of channel orientation and rib pitch-to-height ratio on pressure drop in a rotating square channel with ribs on two opposite surfaces," International Journal of Rotating Machinery, vol. 2005, no. 1, pp. 67-76, 2005. 

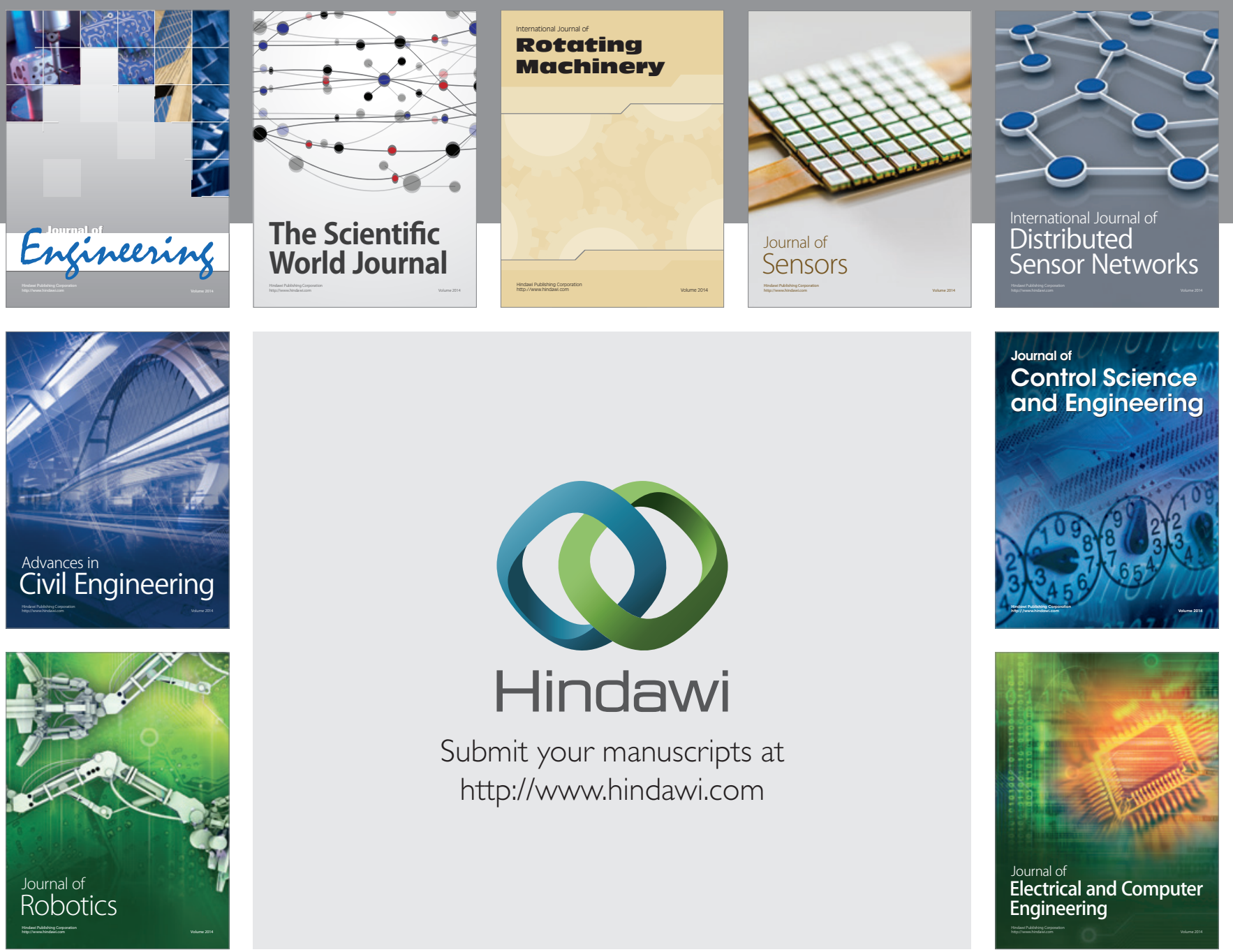

Submit your manuscripts at

http://www.hindawi.com
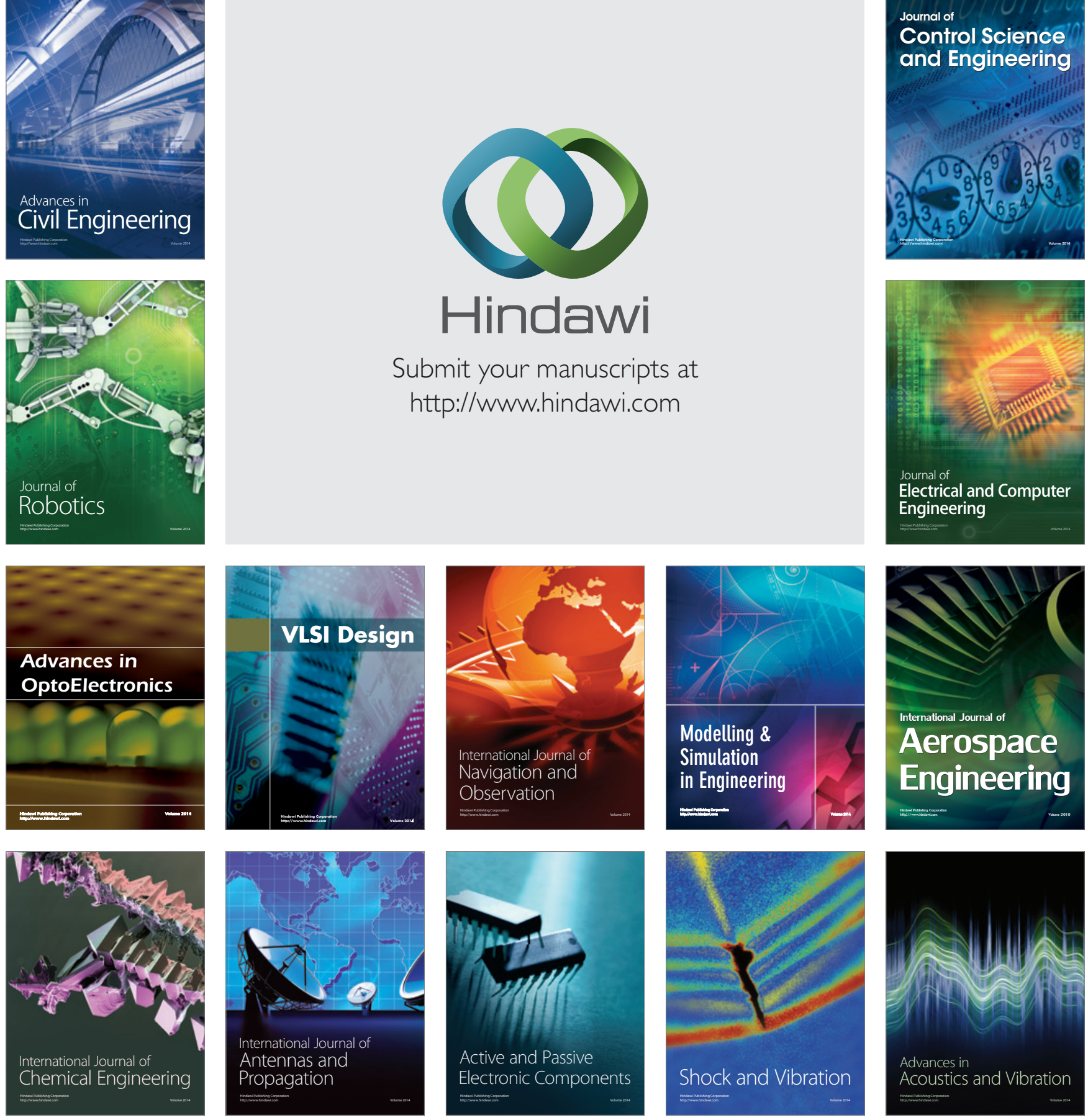